EESTI NSV TEADUSTE AKADEEMIA TOIMETISED 1954. III kd., nr. 3 ИЗВЕСТИЯ АКАДЕМИИ НАУК ЭСТОНСКОИ ССР 1954. Том III, № 3

\title{
ОПЫТ ИЗУЧЕНИЯ ОРГАНИЧЕСКОГО ВЕЩЕСТВА ПРИБАЛТИЙСКИХ СЛАНЦЕВ *
}

\author{
C. C. СЕМЕНОВ, \\ кандидат технических наук
}

Прибалтийские горючие сланцы в настоящее время широко используются в народном хозяйстве как источник энергии, как сырье для производства высококалорийного газа, искусственного жидкого топлива, различных химических продуктов и т. д. Не может быть сомнений в том, что в ближайшие десятилетия значение этих ископаемых возрастет в еще большей степени. Что же касается теоретических вопросов - изучения происхождения сланцев, состава, свойств и строения их органического вещества, приходится констатировать, что здесь имеет место серьезное отставание от практики использования горючих сланцев. Между тем глубокое изучение органического вещества горючих сланцев будет содействовать все более широкому использованию их с целью пронзводства все новых и новых видов сырья и товаров народного потребления.

Приступая к изучению органического вещества прибалтийских горючих сланцев, прежде всего следует определить цели, к которым надо стремиться. Мы считаем, что главной задачей изучения органического вещества является всестороннее раскрытие многообразных его свойств, проявляющихся в различных технологических процессах и особенно при термическом его разложении.

Органическое вещество прибалтийских горючих сланцев содержит до $14 \%$ гетероатомов: кислорода, серы, азота и хлора, причем содержание кислорода достигает $11 \%$ на кероген.

Совершенно естественно поэтому предположить, что свойства керогена в значительной степени определяются наличием гетероатомов; или, точнее, содержащимся в его составе кислородом.

Вероятно, кислород, как и другие гетероатомы, входящие в состав керогена, связан с углеродом и водородом. Теоретически возможными формами связи кислорода с углеродом и водородом могут быть формы в виде карбоксильной, гидроксильной (спиртовой и фенольной), карбонильной, сложноэфирной (или лактонной), ангидридной, простой эфирной (вообще мостиковый кислород) функциональных группировок.

В научно-технической литературе по прибалтийским сланцам по существу не приводится каких-либо данных по обнаружению и определению

* Доклад на второй расширенной научной сессии Отделения технических и физико-математических наук АН ЭССР по вопросам использования горючих сланцев 23 -26 марта 1954 г. 
указанных функциональных, кислородсодержащих группировок, в то время как такие исследования имеют бесспорный, первостепенный теоретический и практический интерес. Наличие сведений о функциональных группировках в органическом веществе позволит не только правильно оценить объект изучения как высокомолекулярный, полифункциональный органический комплеқс, но и понять специфику и все многообразие свойств его в условиях термического разложения и других процессов, ближе подойти к пониманию строения этого комплекса и даже иметь более глубокое представление о материнском веществе, образовавшем кероген горючих сланцев.

Придавая большое значение вопросу обнаружения и определения кислородсодержащих функциональных группировок, мы провели соответствующие исследования, показавшие, что органическое вещество прибалтийских сланцев содержит карбоксильные, гидроксильные, карбонильные и метоксильные функциональные группировки. Кроме того, выяснилось, что кероген содержит также значительное количество потенциальнокислых, омыляемых спиртовой щелочью группировок. Характер этих группировок до настоящего времени еще не выяснен, однако имеются основания предполагать, что большая доля их, повидимому, приходится на сложноэфирные группировки при возможном присутствии ангидридных форм.

Следует иметь в виду, что количественное определение различных функциональных групп находится в прямой зависимости от степени измельчения керогена, от применяемых методов и реагентов.

Для определения карбоксильной группы был применен общеизвестный метод ионного обмена с уксуснокислым кальцием $\left({ }^{8,9}\right)$. К навеске концентрата сланца, полученного флотацией по методу Рембашевского и Проскурякова $\left({ }^{6}\right)$ в количестве 2 г, добавлялось 50 мл $5 \%$ раствора уксуснокислого кальция. Параллельно ставилась холостая проба с дестиллированной водой. После трехдневной выдержки от каждой из проб отбиралось некоторое количество раствора и производилось титрование щелочью в присутствии фенолфталеина. В результате титрования выделившейся уксусной кислоты было установлено, что к органическому веществу присоединяется 0,326 миллиграммэквивалента кальция на грамм органического вещества, что соответствует $1,5 \%$.карбоксильной группы в керогене.

Для определения гидроксильной группы применялись методы ацетилирования в среде пиридина и метилирования диметилсульфатом в щелочной среде с последующим определением метоксильных групп.

При ацетилировании уксусным ангидридом количество гидроксильной группы на кероген в различных образцах колеблется от 1,30 до 3,7\%.

При метилировании диметилсульфатом метоксильное число возрастает с $0,53 \%$ для исходного концентрата до $1,24 \%$ после метилирования. Таким образом, обоими методами обнаруживается гидроксильная группа, хотя количественно ее содержание нельзя признать точно установленным.

Следует заметить, что после обработки органического вещества спиртовой щелочью и последующего метилирования диметилсульфатом метоксильное число возрастает с 1,24 до 1,69 , что свидетельствует о наличии сложноэфирных группировок.

Карбонильная группа определялась фенилгидразиновым методом, причем было установлено ее содержание в количестве около 0,3-0,5\% на органическое вещество.

Большой интерес представляют данные действия спиртовой щелочи на органическое вещество. Эти данные показывают, что кероген прибал- 
тийских сланцев содержит значительные количества кислых и потенциальнокислых функциональных группировок.

От действия спиртовой щелочи кероген сланца быстро изменяет интенсивность окрашивания, доходя до темнокоричневого, почти черного цвета. Обработке спиртовой щелочью подвергался исходный концентрат органического вещества с различным содержанием минеральной части, а также выделенные нами светлая и темная разновидности керогена.

Обработка различных образцов органического вещества производилась спиртовым раствором едкого натра и кали в запаянных трубках, с предварительной эвакуацией воздуха из трубок. Опыты производились при нагревании на кипящей водяной бане и при комнатной температуре, причем предельные значения поглощенной щелочи при той и другой температурах были одни и те же.

Данные опытов приводятся в таблицах 1 и 2.

Таблица 1

Поглощенне едкого кали 96-процентным концентратом органического вещества и его разновидностями при температуре кипения этилового спирта (в миллиграммэквивалентах на грамм органического вещества)

\begin{tabular}{r|c|c|c}
\hline $\begin{array}{c}\text { Bремя } \\
\text { в мин. }\end{array}$ & $\begin{array}{c}96 \% \text { концент- } \\
\text { рат органиче- } \\
\text { ского вещества }\end{array}$ & $\begin{array}{c}\text { Светлая разно- } \\
\text { видность } \\
\text { (содержание } \\
\text { золы } 4,43 \% \text { ) }\end{array}$ & $\begin{array}{c}\text { Темная разно- } \\
\text { видность (содер- } \\
\text { жание золы } \\
4,62 \% \text { ) }\end{array}$ \\
\hline 1 & & & \\
5 & 0,43 & 2,01 & 1,54 \\
15 & 0,95 & 2,03 & 1,54 \\
30 & 1,10 & 2,11 & 1,44 \\
60 & 1,52 & 2,19 & 1,49 \\
120 & 2,03 & 2,11 & 1,49 \\
180 & 2,03 & 2,11 & 1,48 \\
240 & 2,03 & 2,08 & 1,49 \\
360 & 2,03 & 2,19 & 1,49 \\
& & & 1,48
\end{tabular}

Таблица 2

Поглощение 2-процентной щелочн концентратами с различной зольностью, при комнатной температуре (в миллиграммэквивалентах на грамм органического вещества)

\begin{tabular}{|c|c|c|c|c|c|c|}
\hline \multirow{2}{*}{$\begin{array}{l}\text { Время } \\
\text { в час. }\end{array}$} & \multicolumn{2}{|c|}{$\begin{array}{c}\text { Концентрат № } 1 \text { (содер- } \\
\text { жание золы } 14,29 \% \text { ) }\end{array}$} & \multicolumn{2}{|c|}{$\begin{array}{c}\text { Концентрат 스 } 2 \text { (содер- } \\
\text { жание золы } 12,22 \% \text { ) }\end{array}$} & \multicolumn{2}{|c|}{$\begin{array}{c}\text { Концентрат 스 } 3 \text { (содер- } \\
\text { жание золы 4,03\%) }\end{array}$} \\
\hline & $\mathrm{KOH}$ & $\mathrm{NaOH}$ & $\mathrm{KOH}$ & $\mathrm{NaOH}$ & $\mathrm{KOH}$ & $\mathrm{NaOH}$ \\
\hline $\begin{array}{r}2 \\
4 \\
6 \\
8 \\
10 \\
22 \\
35 \\
70\end{array}$ & $\begin{array}{l}1,37 \\
1,43 \\
1,49 \\
1,89 \\
2,20 \\
2,20 \\
2,20 \\
2,20\end{array}$ & $\begin{array}{l}0,97 \\
1,47 \\
1,61 \\
1,81 \\
2,21 \\
2,21 \\
2,21 \\
2,21\end{array}$ & $\begin{array}{l}1,34 \\
1,53 \\
1,75 \\
2,05 \\
2,06 \\
2,06 \\
2,05 \\
2,05\end{array}$ & $\begin{array}{l}1,01 \\
1,54 \\
1,59 \\
2,06 \\
2,17 \\
2,29 \\
2,29 \\
2,29\end{array}$ & $\begin{array}{l}1,73 \\
1,93 \\
1,93 \\
1,93 \\
2,20 \\
2,20 \\
2,20 \\
2,20\end{array}$ & $\begin{array}{l}1,07 \\
2,22 \\
2,38 \\
2,38 \\
2,49 \\
2,49 \\
2,49 \\
2,49\end{array}$ \\
\hline
\end{tabular}

Приведенные данные по содержанию функциональных групп в органическом веществе имеют значение по двум причинам. Во-первых, они кладут конец сложившемуся представлению о керогене как о веществе инертном в химическом отношении. Эти данные раскрывают причину своеобразного поведения сланцев в различных температурных условиях и при контакте с различными реагентами. Характер термического раз- 
ложения, особенно при умеренных температурах (до $380^{\circ}$ ), и продукты разложения могут быть объяснены превращениями функциональных групп.

Во-вторых, и это наиболее важно, обнаружение и относительное количественное определение функциональных групп открывает новые возможности для более глубокого познания керогена сланца и механизма его термического разложения. Механизм первичных форм разложения органического вещества сланца нельзя представить без существенного, может быть решающего участия функциональных групп, распадающихся с выделением воды, окиси и двуокиси углерода, водорода и других продуктов. Зная характер функциональных групп в керогене, очевидно, можно воздействовать на них теми или иными химическими реагентами и тем самым умерить или стимулировать их активность при термическом разложении. Проведенные в этом направлении опыты подтвердили высказанные теоретические представления. При воздействии на кислые и потенциальнокислые (сложноэфирные и ангидридные) группировки спиртовой щелочью и последующем термическом разложении образца в алюминиевой реторте получается смола, практически не содержащая кислых компонентов. Одновременно в составе газа появляется в 3 раза большее количество углекислоты н в 2,5 раза большее количество водорода, что свидетельствует о серьезном изменении механизма распада.

Увеличение углекислоты в газе следует объяснить распадом карбоксильных групп, образовавшихся при омылении сложноэфирных и ангидридных функциональных группировок керогена. Увеличение содержания свободного водорода в газе полукоксования образца, обработанного щелочью, объясняется распадом фенольных структур керогена, по аналогии с распадом фенолятов различных металлов, как это установили Фишер и др. $(14,11)$.

В таблице 3 приводятся данные по выходу продуктов полукоксования исходного керогена иं керогена, предварительно обработанного спиртовой щелочью, отнесенные на органическое вещество.

Таблица 3

\begin{tabular}{|c|c|c|c|c|c|c|c|c|c|}
\hline \multirow[b]{2}{*}{$\begin{array}{l}\text { Наимено- } \\
\text { вание } \\
\text { образца }\end{array}$} & \multirow[b]{2}{*}{$\begin{array}{c}\text { Содержание } \\
\text { керогена в } \\
\text { образце \% }\end{array}$} & \multicolumn{8}{|c|}{$\begin{array}{c}\text { Продукты полукоксования в \% на органи- } \\
\text { ческое вещество }\end{array}$} \\
\hline & & 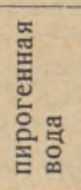 & 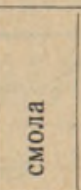 & 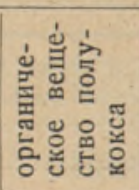 & 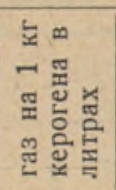 & 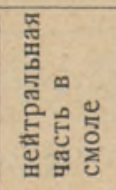 & 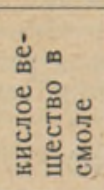 & 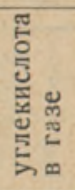 & 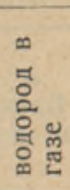 \\
\hline $\begin{array}{l}\text { Исходный } \\
\text { образец } \\
\text { Образец, } \\
\text { обработан- } \\
\text { ный щелочью }\end{array}$ & 95,05 & 6,0 & 62,8 & 16,85 & 71,0 & 48,9 & 13,9 & 1,50 & 0,06 \\
\hline
\end{tabular}

Твердые горючие ископаемые подразделяются на сапропелитовые, гумусовые и смешанные образования. Пронсхождение сапропелитовых ископаемых обычно связывается с жировым исходным материалом, в то время как гумусовые относятся к растительным материалам, бедным жировыми веществами. В связи с этим сапропелитовые образования как бы лишаются права иметь в своем составе циклические и, особенно, ароматические структуры, а гумусовые образования, наоборот, характеризуются прежде всего наличием ароматических структур. Общепризнано положение, что при сухой перегонке сапропелитовых ископаемых должно 
нолучаться большое количество смолы, не содержащей фенолов и ароматических углеводородов, а гумусовые образования должны давать меньший выход смолы с бо́льшим содержанием фенолов и ароматических углеводородов.

Органическое вещество прибалтийских сланцев большинством исследователей относится к сапропелитовым образованиям. Однако состав смолы полукоксования оказывается не типичным для смол сапропелитов, так как в ней содержится до $20 \%$ фенолов и большое количество ароматических углеводородов, как в легких, так и в высококипящих фракциях. Это обстоятельство вынудило Стадникова $\left({ }^{7}\right)$ «признать наличие в органической массе последних (кукерситов - С. С.) примеси гумусового материала». Необходимо заметить, что Стадников рассматривал кислые вещества в смолах как «смесь циклических двуатомных алкоголей и, вероятно, кетоалкоголей, растворяющихся в водной едкой щелочи». Содержание фенолов в смолах полукоксования, по мненню Стадникова, «крайне незначительно».

Такая точка зрения, по нашему мнению, ошибочна. Сапропелитовые ископаемые на определенном этапе генетических превращений имеют циклические, включая ароматические, структуры, в числе которых не исключена возможность наличия и фенольных структур, которые при сухой перегонке могут дать фенолы, ароматические, нафтеновые и другие циклические углеводороды и их гетероатомные производные.

Кероген прибалтийских сланцев на протяжении своей истории не испытывал воздействия повышенных температур и накапливался в условиях высокой минерализации вод, имеющих щелочную реакцию. Следовательно, отлагающийся органический материал попадал в условия естественной консервации и поэтому не подвергался глубоким изменениям. В этой связи следует напомнить работу Залесского (1), блестяще доказавшего удивительную сохранность открытой им водоросли Gloeocapsamorfa prisca, не утратившей способности к набуханию и развертыванию в подходящей среде. Цвет и распределение органического вещества в сланцах в свою очередь подтверждают отсутствие глубоких процессов разложения и биохимического воздействия микроорганизмов. Следовательно, можно предположить, что кероген представляет собой хорошо сохранившийся органический материал, входящий в состав некогда жившей водоросли.

Его сохранности способствовали низкие температуры, высокая минерализация вод, а затем и породы, наличие антисептизирующих функциональных группировок и фенольных структур. Последнее обстоятельство очень важно и поэтому ниже будут приведены соответствующие факты, доказывающие наличие фенольных и вообще циклических структур в керогене.

Для доказательства наличия ароматических структур в горючих ископаемых применяют разработанный Боном $\left({ }^{12}\right)$ метод окисления марганцевокислым калием в щелочной среде, причем соединения, имеющие открытое строение, окисляются до воды и углекислоты. В случае наличия ароматических циклов реакция окисления останавливается на стадии образования бензолкарбоновых кислот, устойчивых в условиях окисления.

Таким образом, если при окислении горючего ископаемого получаются бензолкарбоновые кислоты, наличие бензольных (ароматических) структур счнтается доказанным. Однако отсутствне бензолкарбоновых кислот в продуктах окисления не является доказательством отсутствия ароматических структур в окисляемом веществе, поскольку ряд веществ, имеющих такие структуры, при окислении не дает бензолкарбоновых кислот. 
К числу таких веществ, по данным Рандаля и др. $\left({ }^{15}\right)$, относятся кумарон, конифериловый альдегид, 1-метокси-2-альдометокси-бензолдиэтилацеталь и др. По данным Караваева $\left({ }^{2}\right)$, формальдегидрезорциновая смола и, по данным Миклашевской $\left({ }^{5}\right)$, фенолы также не дают бензолкарбоновых кислот.

Повидимому, все вещества, в которых один или несколько углеродных атомов ароматического кольца имеют связь с гетероатомами (кислород, сера и др.), не способны давать бензолкарбоновых кислот. Бензольное кольцо в этих случаях оказывается непрочным в отношении окислителя и разрушается.

Окислению керогена прибалтийских сланцев марганцевокислым калием в щелочной среде по Бону были посвящены работы Кокурина (диссертация, 1938 г.), Ланина и Прониной $\left({ }^{4}\right)$, Химуса $\left({ }^{13}\right)$, Когермана с сотрудниками $\left({ }^{3}\right)$, а также Фоминой и Побуль $\left({ }^{10}\right)$. Окислением пиробитума в тех же условиях занимались Караваев и Венер $\left({ }^{2}\right)$.

Во всех перечисленных работах утверждается, что в продуктах окисления не было обнаружено бензолкарбоновых кислот. Главными продуктами окисления керогена и битума были углекислота и щавелевая кислота. Кроме этих продуктов, всеми исследователями были обнаружены небольшие количества летучих одноосновных и нелетучнх двуосновных кислот нормального строения и высшие нелетучие кислоты неустановленного строения, содержащие в своем составе серу и азот.

Следует особо отметить многолетнюю, весьма интересную работу Фоминой и Побуль, применивших более мягкие условия окисления и получивших значительно бо́льшие выходы летучих и нелетучих кислот. Из одноосновных кислот ими индивидуализированы нормальные кислоты от $\mathrm{C}_{2}$ до $\mathrm{C}_{8}$ и из нелетучих двуосновных, тоже нормального строения, кислоты от $\mathrm{C}_{2}$ до $\mathrm{C}_{10}$.

Промежуточные продукты окисления, или промежуточные кислоты, по данным элементарного анализа, авторами относятся к производным циклопарафинов с боковыми цепями.

Таким образом, можно констатировать, что метод окисления марганцевокислым калием в разных условиях пока не дал прямого ответа на вопрос - имеются ли в керогене ароматические или вообще циклические структуры.

Между тем в настоящее время имеются все основания утверждать наличие ароматических структур в керогене. Таким основанием является ненасыщенный характер органического вещества сланцев, о чем свидетельствует его элементарный состав.

Для выяснения характера строения органических соединений на основании их элементарного анализа обратимся к веществам, содержащим только углерод и водород, т. е. к углеводородам.

В этом случае для каждого класса или гомологического ряда имеет место строгое соответствие между числом валентностей углерода, потраченных на образование углеродного скелета молекулы, и числом валентностей, пошедших на связь с водородом.

Это соответствие определяется насыщенностью углеводорода: чем более насыщенный углеводород, тем меньшее число валентностей углерода приходится на образование углеродных связей в молекуле.

Минимум углеродных связей, при одном и том же числе углеродных атомов в молекуле, приходится на предельные (парафиновые) углеводороды. В этом классе углеводородов число углеродных связей равно числу углеродных атомов в молекуле без единицы. Для углеводородов, имеющих ненасыщенный состав, число углеродных связей тем больше, чем выше их ненасыщенность. Истинное число углеродных связей углеводо- 
рода любой насыщенности водородом может быть рассчитано на основании его элементарного состава по єледующей теоретической, выведенной нами формуле:

$$
X_{p \phi}=\frac{\left(\frac{\mathrm{C}}{3}-\mathrm{H}\right) M}{2 \cdot 100}
$$

где $X_{p \phi}$ - расчетное (р) и фактическое (ф) число углеродных связей в молекуле;

С и $\mathrm{H}$ - содержание углерода и водорода в процентах;

M - молекулярный вес.

Для насыщенного углеводорода с открытой цепью число углеродных связей может быть определено по формуле

$$
X_{0}=\frac{\mathrm{C} M}{12 \cdot 100}-1
$$

где $X_{0}$ - число углеродных связей в гипотетическом углеводороде с тем же числом углеродных атомов в молекуле, имеющем насыщенный состав и открытое строение.

Из уравнений (1) и (2) следует:

$$
X_{p \phi}-X_{0}=\frac{\left(\frac{\mathrm{C}}{3}-\mathrm{H}\right)^{M}}{2 \cdot 100}-\left(\frac{\mathrm{C} M}{12 \cdot 100}-1\right) \text {. }
$$

Полученная разность $X_{p \phi}-X_{0}$ показывает степень ненасыщенности или цикличности и позволяет составить представление о строении исследуемого вещества.

Заметим, что, зная элементарный состав вещества, во многих случаях возможно определить истинный молекулярный вес вещества.

В случае веществ, содержащих в своем составе, кроме углерода и водорода, гетероатомы (кислород, серу, азот и т. д.), уравнение (1) для расчета числа углеродных связей будет иметь вид:

$$
\begin{aligned}
X_{p \phi \phi}=\left\{\frac{\mathrm{C}}{3}-[\mathrm{H}\right. & +\frac{n_{1}\left(\mathrm{O}_{0}-\Sigma \mathrm{O}_{\phi \phi}\right)}{16}+\frac{n_{2}\left(\mathrm{~N}_{0}-\Sigma \mathrm{N}_{\phi \phi}\right)}{14}+\frac{n_{3}\left(\mathrm{~S}_{0}-\Sigma \mathrm{S}_{\phi \phi}\right)}{32}+ \\
& \left.\left.+\frac{\mathrm{Cl}(\mathrm{Br}, \mathrm{S})}{35,46(80 ; 127)}+\text { и т. д. }\right]\right\} \frac{M}{2 \cdot 100},
\end{aligned}
$$

где $\mathbf{\Sigma O}_{\phi}, \geq \mathrm{N}_{\phi}, \mathbf{\Sigma} \mathrm{S}_{\phi}$ - гетероатомы (кислород, азот, сера), требующие внесения поправки на функциональность;

$\mathrm{O}_{0}, \mathrm{~N}_{0}, \mathrm{~S}_{0}$ - общее содержание гетероатомов (кислорода, азота, серы);

$n_{1}, n_{2}, n_{3}$ - валентности гетероатомов в данном соединении.

Имея уравнения (2) и (4), по которым можно произвести расчет числа углеродных связей, определим степень цикличности керогена прибалтийских сланцев, предположив, что кероген не имеет обычных олефиновых связей (исключая двойные связи в ароматических циклах).

\begin{tabular}{|c|c|c|c|}
\hline углерода & $-77,61$ & кислорода (прямым & \\
\hline водорода & $-9,15$ & определением) - & 11,3 \\
\hline еры орг. & 1,39 & $\begin{array}{l}\text { азота } \\
\text { хлора }\end{array}$ & $\begin{array}{l}0,1 \\
0,3\end{array}$ \\
\hline
\end{tabular}

В нашем распоряжении имеются многочисленные данные элементарных анализов керогена, полученные разными исследователями.

Возьмем один из таких анализов, по которому органическое вещество содержит (в процентах): 
Подставляя данные в соответствующие уравнения, получим (для расчета условно принят молекулярный вес 1000):

$$
\begin{gathered}
X_{p \phi}=\frac{\frac{77,61}{3}-\left[9,15+\frac{11,37}{8}+\frac{1,39}{16}+\frac{3.0,18}{14}+\frac{0,3}{35 \cdot 5}\right]}{2 \cdot 100} \cdot 1000=75,8 . \\
X_{0}=\frac{77,61 \cdot 1000}{12 \cdot 100}-1=63,7 ; X_{p \phi}-X_{0}=12,1 .
\end{gathered}
$$

Следует заметить, что при расчете величины $X_{p \phi}$ поправки на функциональность гетероатомов не внесены, чем значительно занижено число углеродных связей, а вместе с тем занижена и разность $X_{p \phi}-X_{n}$.

Поскольку кероген сланца не имеет олефиновых двойных связей, а разность $X_{p \phi}-X_{0}$ имеет ноложительное значение (минимально 12,1 ), можно утверждать, что эта разность обусловлена наличием циклических структур в керогене.

Для выяснения класса цикличности керогена произведем соответствующие расчеты.

Предположим, что кероген содержит нафтеновые, неконденсированные циклы, имеющие шесть углеродных атомов в кольце. При разности $X_{p \phi}-X_{0}=12,1$ (на произвольный молекулярный вес 1000) будем иметь количество углерода в циклах $12 \times 6 \times 12,1=871,2$ г, или $87,12 \%$ на кероген.

Фактическое содержание углерода равно $77,61 \%$, следовательно возможность наличия только нафтеновых, неконденсированных циклов отпадает.

Предположим далее, что кероген имеет в своем строении конденсированные, полиметиленовые структуры в виде цепочки шестичленных циклов

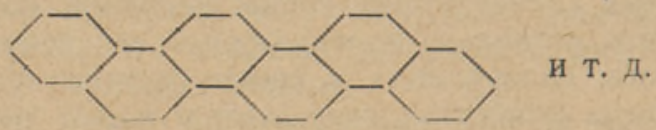

В этом случае для получения разности $X_{p \phi}-X_{0}=12,1$ необходимо иметь 15 циклов, что будет соответствовать $12 \times 62=744$ г углерода в циклах.

Учитывая выходы и состав продуктов полукоксования, а также характер продуктов окисления керогена, следует признать и такое строение не соответствующим действительности. Более вероятные результаты получаются в случае предположения в керогене ароматических структур. В этом случае на 1000 г керогена должно приходиться минимально только 3 ароматических цикла, что будет соответствовать 216 г углерода в циклах, остальной же углерод размещается в боковых цепях. Воз-

\begin{tabular}{|c|c|c|c|c|c|c|}
\hline \multirow{2}{*}{$\begin{array}{l}\text { Наименование } \\
\text { образца }\end{array}$} & \multicolumn{3}{|c|}{$\begin{array}{c}\text { Әлементарный состав } \\
\text { в \% }\end{array}$} & \multicolumn{2}{|c|}{$\begin{array}{c}\text { Число углерод- } \\
\text { ных связей }\end{array}$} & \multirow{2}{*}{$\begin{array}{c}\text { Показатель } \\
\text { циклич- } \\
\text { ности } \\
X_{p \phi}-X_{0}\end{array}$} \\
\hline & C & $\mathrm{H}$ & $\mathrm{O}+\mathrm{N}+\mathrm{S}$ & $X_{p \phi \phi}$ & $X_{0}$ & \\
\hline $\begin{array}{l}\text { Пласт } A \\
\text { Пласт } B \\
\text { Пласт } C \\
\text { Пласт } D \\
\text { Пласт } E \\
\text { Между } B \text { и } C \\
\text { Средний образец }\end{array}$ & $\begin{array}{l}77,49 \\
76,25 \\
76,47 \\
76,87 \\
76,93 \\
77,56 \\
76,60\end{array}$ & $\begin{array}{l}9,13 \\
9,10 \\
9,20 \\
9,32 \\
9,30 \\
9,42 \\
9,20\end{array}$ & $\begin{array}{l}12,7 \\
14,15 \\
13,69 \\
13,18 \\
13,23 \\
13,02 \\
14,20\end{array}$ & $\begin{array}{l}76,7 \\
73,5 \\
73,8 \\
72,7 \\
74,5 \\
74,8 \\
73,8\end{array}$ & $\begin{array}{l}63,6 \\
63,5 \\
62,7 \\
53,0 \\
63,1 \\
63,6 \\
62,8\end{array}$ & $\begin{array}{r}13,1 \\
10,0 \\
11,1 \\
9,7 \\
11,4 \\
11,2 \\
11,0\end{array}$ \\
\hline
\end{tabular}

таблица 4 
можно, впрочем, и меньшее количество ароматических циклов при условии одновременного присутствия в керогене и нафтеновых колец.

Аналогичные расчеты нами произведены для большого количества образцов керогена прибалтийских сланцев, причем во всех случаях (более 100) показатель цикличности оказался положительным. В таблице 4 приведены некоторые из этих расчетов.

Всестороннее рассмотрение имеющихся о керогене данных приводит к заключению о присутствии в нем ароматических структур. На первый взгляд такой вывод может показаться недостаточно обоснованным, так как при наличии ароматических структур при окислении керогена должны были бы получаться бензолкарбоновые кислоты. Однако, с учетом того, что не все ароматические структуры приводят к образованию бензолкарбоновых кислот, такое заключение можно считать единственно правильным. В самом деле, достаточно иметь в ароматических циклах гидроксильную группу, как вопрос образования бензолкарбоновых структур отпадает сам собой. В этом случае действие окислителя в первую очередь направляется на ослабленное ароматическое кольцо. Последнее разрушается с образованием углекислоты и щавелевой кислоты. Другие звенья керогеновой молекулы, повидимому, вступают во взаимодействие с окислителем после разрушения ароматической структуры. Такая интерпретация реакций окисления прямо связана с возможностью образования одно- и двуосновных карбоновых кислот нормального строения любого молекулярного веса.

Поскольку кероген содержит в своем составе до $14 \%$ гетероатомов, последние, повидимому, в основной своей массе размещены в боковых цепях нормального строения в виде конечных функциональных групп (карбоксильных, сложноэфнрных, ангидридных). Разрушение окислителем ароматического кольца кладет начало другой карбоксильной группе. В случае же боковой цепи углеводородного характера при окислении получается одноосновная кислота. Также находит объяснение образование промежуточных кислот, содержащих азот и серу. Эти кислоты представляют собой продукты первой фазы окисления керогена, когда окислитель по существу воздействовал только на ароматическое кольцо. Факт неизменности элементарного состава остаточного после окисления керогена также подтверждает изложенную точку зрения.

В случае термической деструкции ароматические структуры обладают наибольшей прочностью. Здесь имеет место обратная направленность процесса. Термический распад в первичных его формах начинается с конечных гетероатомных функциональных групп в боковых цепях с выделением углекислоты и воды. Фенольные группировки, имеющиеся в керогене, после отрыва части боковых заместителей частично дестиллируются и, в конечном счете, появляются в смоле, а частично конденсируются с образованием кокса. Наличие в смолах полукоксования до $20 \%$ фенолов, а также исчезновение их при предварительной обработке керогена спиртовой щелочью подтверждает высказанные соображения. Следует также напомнить работу Караваева и Венера $\left({ }^{2}\right)$, в которой было показано, что пиробитум из прибалтийского сланца имеет фенольные структуры.

\section{Выводы}

1. На основании соответствующих анализов в керогене прибалтийских сланцев доказано наличие следующих функциональных групп:

а) карбокскльной (методом нонного обмена),

б) гидроксильной (методами ацетилирования и метилирования диметилсульфатом), 
в) карбонильной (фенилгидразиновым методом),

г) омыляемых - сложноэфирных и ангидридных группировок (методом омыления спиртовой щелочью),

д) метоксильных групп (по Гейзелю).

Относительные количественные определения указанных выше группировок показывают, что в органическом веществе сланца доминирующее значение имеют кислые (карбоксильные и гидроксильные) и потенциальнокислые (сложноэфирные и ангидридные) группировки.

2. На основании расчета числа углеродных связей в органическом веществе сланца по выведенным нами теоретическим уравнениям. доказано наличие циклических, ароматических структур. По предварительным данным можно полагать, что количество углерода, находящегося в ароматических циклах, достигает $20-25 \%$ общего углерода в органическом веществе.

3. На основании опытов термического разложения керогена, предварительно обработанного спиртовой щелочью, непосредственного определения гидроксильных групп, а также на основании литературных данных по окислению керогена и пиробитума можно считать, что ароматические структуры представлены в виде фенолсодержащих структур с боковыми цепями, преимущественно нормального строения. Последние, в свою очередь, имеют гетероатомные окончания в виде сложноэфирных и ангидридных группировок.

При окислении таких спруктур марганцевокислым калием получаются одно- и двуосновные кислоты нормального строения.

Первичные формы окислительной деструкции представляются в виде разрыва гидроксилсодержащего ароматического ядра, чем закладывается начало карбоксильной группы со стороны цикла. С учетом наличия гетероатомных окончаний боковых цепей в последующих стадиях окисления образуются двуосновные кислоты нормального строения. Образование промежуточных кислот, содержащих азот и серу, следует рассматривать как первую фазу воздействия окислителя на кероген, когда происходит разрыв углеродных связей толыко ароматического кольца.

При термическом разложении первичные формы распада начинаются c разложения гетероатомных группировок с образованием углекислоты и воды. При углублении термического воздействия образуются углеводороды и их производные с содержанием большого количества высших фенолов, а также кокс и газы.

Таким образом, термическая и окислительная деструкции органического вещества сланца различаются направленностью начальных форм распада. В первом случае начальные формы распада идут в боковых цепях, во втором - в ароматических, гидроксилсодержащих циклах.

В работе принимали участие научные сотрудники Ю. И. Корнилова, Б. Е. Гуревич, Н. С. Орлова и лаборанты А. И. Николаева и А. С. Денисова.

Всесоюзный научно-исследовательский институт по переработке сланцев

\section{ЛИТЕРАТУРА}

1. М. Д.- 3 а лесски й, О морском сапропеле силурнйского возраста, образованном синезеленою водорослью. Изв. имп. Акад. наук, серия VI, т. XI, 1917.

2. Н. М. К а ра в а е в и И. М. В ен е р, О битуме гдовского сланца, Труды ИГи AH CCCP, T. II, 1950.

3. П. К. Когерм ан, Окисление сланцев как метод исследования химической природы керогена. Изв. АН ЭССР, № 1, 1952. 
4. В. А. Л анин и М. В. Пронин а, Об органическом веществе горючих сланцев. Изв. АН СССР, ОТН, № 10-11, 1944.

5. С. И. Ми клошев в ка я, Метод определения фенола и крезолов при совместном присутствии, «Химия твердого топлива» № 6, 1934.

6. А. Г. Рембашевский, В. А. Проскуряков, Обогащение прибалтийских горючих сланцев, «За экономию топлива», № $12,1951$.

7. Г. Л. Стадников, Органическая масса горючих сланцев, «Химия твердого топлива», № 1, 1934.

8. Г. Л. Стаднн ков, Химия угля, Гос. научно-те́хн. изд., 1932.

9. К. Н. С ы сков, Г. А. К у х а р ен ко, Определение конститутивных групп в углях и их составных частях сорбционным способом, «Заводская лаборатория», № $1,1947$.

10. А. С. Фомина и Л. Я. Побуль, Окислительная деструкция керогена кукерсита. Изв. АН ЭССР, № $1,1953$.

11. Ч. Д. Херд, Пиролиз соединений углерода, ГОНТИ, 1938.

12. W. A. B on e a. o., Journ. of the Society of Chemical Ind., p. 407, 1931.

13. A. L. Dow $n$ and G. W. H i m u s, A Preliminary Study of the Chemical Constitution of Kerogen. Journal of the Institute of Petroleum, Vol. 27, 1941.

14. F. Fischer, I. Ehrhardt, Gesammelte Abhandlungen zur Kenntnis der Kohle, Bd. IV, S. 237, 1920.

15. R. B. Randa11, M. B enger and C. M. Groocock, Researches on the Chemistry of Coal. Proceedings of the Royal Society, Series A. Vol. 165, No 992, 1938. 